\title{
EVIDÊNCIAS LINGUÍSTICO-CULTURAIS DE RESISTÊNCIA NA LITERATURA INFANTIL PÓS- COLONIAL: LITERATURA SURDA E ONDJAKI
}

\author{
Sonia Maria Gomes Sampaio* \\ Universidade Federal de Rondônia \\ Larissa Gotti Pissinatti** \\ Universidade Federal de Rondônia
}

\begin{abstract}
Resumo: Este artigo identifica as representações linguístico-culturais de resistência na narrativa Adão e Eva dos autores Lodenir Karnopp e Fabiano Rosa, da literatura surda e na obra Ynari: a menina de cinco tranças do autor angolano Ondjaki. Para tanto, usamos a abordagem comparativista trazendo as evidências de resistência nas obras a partir dos estudos pós-coloniais. $\mathrm{Na}$ primeira parte do artigo contextualizamos as obras e após abordamos o termo resistência a partir dos estudos pós-coloniais e, em seguida adentramos na análise das obras. A fim de delimitar os elementos de análise para comparação das obras, fizemos uso de alguns aspectos da topoanálise elencados por Ozíris Borges Filho, limitando nosso estudo às evidências de resistência manifestadas na obra pelos personagens e pela ambientação criada pelos autores, identificando os valores culturais e linguísticos que são expressos nas obras. Verificamos que tanto Adão e Eva como Ynari possuem elementos textuais que evidenciam valores línguístico-culturais e os autores, fazem da literatura uma estratégia de resistência.

Palavras-chave: Literatura Surda. Ondjaki. Pós-colonialismo. Resistência.
\end{abstract}

Com este artigo pretendemos evidenciar por meio da abordagem comparativista as evidências de resistência linguístico-culturais que as obras Adão e Eva (KARNOPP; ROSA, 2011) e Ynari: a menina de cinco tranças (ONDJAKI, 2010) possuem. Limitar-nos-emos a identificar por meio da topoanálise os personagens principais das respectivas obras e a ambientação criada pelos autores fazendo uma abordagem a partir dos estudos pós-coloniais

Esta obra está licenciada sob uma Creative Commons - Atribuição 4.0

\footnotetext{
* Doutora em Educação, Docente do Departamento de Línguas Vernáculas da Universidade Federal de Rondônia atua no Mestrado Acadêmico em Estudos Literários e Mestrado Acadêmico em Letras; Membro do Grupo de Estudos em Cultura, Educação e Linguagens - GECEL/UNIR/CNPq e do Grupo de Pesquisa Literatura, Educação e Cultura: caminhos da alteridade - LECCA/UNIR/CNPq. Email: <soniagomesampaio@gmail.com>.

${ }^{* *}$ Mestra em Estudos Literários pela Universidade Federal de Rondônia - UNIR; Docente efetiva, vinculada ao Departamento de Línguas Vernáculas, na disciplina de LIBRAS pela UNIR; Membro do Grupo de Estudos em Cultura, Educação e Linguagens - GECEL/UNIR/CNPq e do Grupo de Pesquisa Literatura, Educação e Cultura: caminhos da alteridade - LECCA/UNIR/CNPq. E-mail: <larisssa.pissinatti@unir.br>.
} 
das evidências de resistência que apresentam as narrativas.

Porém, antes de adentramos na análise textual, faremos uma breve contextualização das realidades em que os autores produziram seus textos.

\section{Contextualização das obras: Adão e Eva e Yanari: a menina de cinco tranças}

A literatura surda surge no Brasil por volta da década de 90. Somente em 1999 as primeiras produções são divulgadas por meio de histórias infantis traduzidas para LIBRAS (Língua Brasileira de Sinais). Com o reconhecimento da LIBRAS como língua da comunidade surda brasileira por meio da Lei 10.436 no ano de 2002, as produções literárias da comunidade surda começam a ganhar maior visibilidade favorecendo maior interesse, inclusive por parte do mercado editorial, em lançar obras literárias traduzidas, contribuindo para que os surdos passassem a ter maior acesso à cultura. A literatura surda caracteriza-se por trazer vivências e experiências do "sujeito surdo" inserido em uma comunidade majoritariamente ouvinte, ou seja, é um espaço onde acontece a expressão de experiências visuais por meio de criações, traduções ou traduções adaptadas de contos infantis (KARNOPP, 2010).

Os espaços de produções surdas iniciaram em Federações, Associações e escolas de surdos que possibilitam a esta comunidade um encontro linguístico. A literatura possibilitou aos surdos, dentro destes espaços, uma representação de si, por meio da revelação de seus desejos, vivências; assim, a produção surda é motivada por práticas sociais e linguagem, ligadas aos aspectos cultural, ideológico, histórico e social (KARNOPP, 2010). A literatura surda leva esta denominação por ser criada, traduzida ou adaptada principalmente para a comunidade surda, porém não se restringe somente a este público, como afirma Mourão (2011), ator e pesquisador surdo:

\footnotetext{
não há um conceito definidor de "literatura surda". Quando nos referimos a literatura surda nos colocamos frente às representações discursivas dos surdos, pois “a literatura surda traz histórias de comunidades surdas, e essas histórias não interessam só para elas, mas para comunidades ouvintes, por meio da participação de sujeitos surdos e ouvintes (MOURÃO, 2011, p. 71).
}

Assim como para Mourão (2011), o pesquisador surdo Holcomb (2013), compreende a literatura surda como um fenômeno que reflete as experiências do povo surdo que possuem vivência de transitar em dois mundos, o mundo ouvinte e o mundo surdo. Por essa razão, em geral, essas narrativas apresentam em suas criações e traduções culturalmente adaptadas uma perspectiva positiva do sujeito surdo em relação a sua condição e fortalecimento dos valores linguístico-culturais que compõem os artefatos constitutivos de sua formação (língua, 
costumes e tradições) enquanto membro do povo surdo e sua comunidade.

Strobel (2013), seguindo as ideias de Mourão (2011) e Holcomb (2013), afirma que a literatura surda se constitui como um dos artefatos culturais do povo surdo. Para a autora, artefato é compreendido como "tudo o que se vê e sente quando está em contato com a cultura de uma comunidade como material, vestuário, maneira como se dirige ao outro, tradições, valores, normas, etc.” (STROBEL, 2013, p. 43). Portanto, a literatura surda manifesta através de suas criações e traduções culturalmente adaptadas a forma de ser, pensar e agir do surdo usuário da língua de sinais em relação ao mundo.

A literatura surda se caracteriza por apresentar os valores linguístico-culturais do povo surdo usuário de uma língua específica e com isso valores culturais próprios. A cultura torna-se por meio da literatura um instrumento mediador de sentidos, por meio do qual é possível resistir, questionar e refletir sobre os valores transmitidos pelas instituições sociais. Para Bassnet (2003), a tradução em uma abordagem pós-colonial é um processo dialógico de negociação cultural e relação de poder em que o texto de origem perde seu status de superioridade (BASSNET, 2003, p. 10). Ainda em relação a esta noção de tradução como negociação cultural os teóricos pós-coloniais Ashcroft; Griffiths; Tiffin (2002) e Bonnici (2009), sugerem o termo reescrita. Autores pós-coloniais reescrevem e ao fazê-lo manifestam resistência e crítica em relação aos valores impostos pelo colonizador. Dessa forma, o texto pós-colonial reescrito a partir do texto canônico, com um viés cultural, implanta estratégias contra-discursivas, desconstruindo de forma racionalizada noções colonizadoras (ASHCROFT; GRIFFITHS; TIFFIN, 1991, p. 104).

A partir disso inferimos que, como já afirmou Mourão (2011), ainda não podemos afirmar o que é literatura surda, não temos um conceito definido ou definitivo para tal, nem grande fortuna crítica, pois esse é um momento de transição em que as discussões e as concepções e/ou abordagens estão sendo construídas. Tudo é ainda muito recente. Apesar do já dito, acreditamos que os estudos pós-coloniais abrem uma perspectiva porque tem possibilitado a investigação sistemática da noção de literatura surda como um fenômeno que se manifesta, também, na forma de tradução culturalmente adaptada, logo uma reescrita, uma reinvenção

No caso da literatura surda, as traduções adaptadas trazem -a partir da leitura e contato com textos clássicos- uma releitura cultural, em que especificidades linguísticas e valores do povo surdo são apresentados no decorrer do enredo.

Principalmente nas narrativas adaptadas como é o caso da obra Adão e Eva 
(KARNOPP; ROSA, 2011), Patinho Surdo (KARNOPP; ROSA, 2011), Cinderala Surda (KARNOPP; ROSA; SILVEIRA, 2007), Rapunzel Surda (KARNOPP; ROSA; SILVEIRA, 2011), veremos que ocorrem várias adequações culturais na história aproximando a narrativa da experiência da comunidade surda enquanto comunidade linguísticamente distinta, trazendo valores e costumes que se distinguem da comunidade ouvinte. Estes são elementos que iremos identificar na narrativa adaptada da literatura surda Adão e Eva.

Ondjaki, escritor angolano, também expressa em várias de suas produções literárias infantis, aspectos linguístico-culturais de sua terra natal. Em suas obras manifesta-se o retrato de uma Angola ex-colônia, marcada por guerras, fome, miséria, preconceito, desigualdade social e violência imposta pelo capitalismo europeu que fez o povo angolano perder a voz por muito tempo para Portugal. Somente a partir do século XX o país passa a manifestar-se de forma resistente e não violenta ao colonialismo europeu. Em 11 de novembro de 1975 Angola conquista independência de Portugal, nesse mesmo ano tem início uma guerra civil que durou 27 anos finda em 04 de abril de 2002. Esta realidade sócio-política particulariza-se em várias narrativas infantis de Ondjaki, dentre elas Ynari: a menina de cinco tranças (2010). E outras obras do mesmo autor como: O leão e o coelho saltitão (2009) e $O$ vôo do golfinho (2012). Estas narrativas evidenciam por meio de da fantasia o sofrimento da guerra e a conquista da paz; a fome e o desejo de liberdade, realidades muito presentes na vida das crianças angolanas e sentimentos que também perpassaram a infância do autor.

A obra Ynari: a menina de cinco tranças de Ondjaki e a narrativa Adão e Eva da literatura surda se aproximam, pois, por meio da literatura, evidenciam experiências e vivências de um grupo cultural marcado pela colonização linguística e cultural estrangeira. Os surdos viveram por séculos uma colonização linguística quando obrigados a aprenderem a Língua Portuguesa no Brasil na sua forma falada e escrita, isto trouxe o isolamento social deste grupo, em razão da privação de informações que sofriam por não existir uma efetiva comunicação entre surdos e ouvintes. Somente em 2002, os surdos, com o reconhecimento da LIBRAS como língua natural da comunidade surda, conquistaram o direito de terem acesso à língua de sinais como primeira língua e a língua portuguesa na sua modalidade escrita, ficando a oralidade como uma opção. Já no caso de Ondjaki, a Angola foi colonizada territorialmente pelos portugueses e por muitos anos passou por guerras. A obra Ynari retrata por meio da fantasia o sofrimento de uma menina que deseja por fim a guerra. O livro remete a guerra de Luanda que devastou o país e trouxe muito sofrimento e privação às crianças daquele local. 
Ambas as obras são escritas na língua portuguesa evidenciando na escrita a apropriação linguística da língua em que foram colonizados e hoje a usam para criar um espaço de reflexão e resistência para as próximas gerações. Outro aspecto importante a ser levado em consideração ao adentramos as duas obras é que a obra Adão e Eva evidencia a resistência por meio de uma narrativa adaptada enquanto a narrativa Ynari trata de uma criação, porém ambas apesar de serem da modalidade literatura-infantil, não se destinam somente a este público, devido a grande quantidade de evidências linguístico-culturais que são manifestadas em ambas obras.

Apresentaremos pelo viés dos estudos pós-coloniais como estas obras podem manifestar evidências de resistência. A teoria pós-colonial contribui para compreendermos onde se situam essas narrativas nos estudos literários na contemporaneidade e a topoanálise nos auxiliará na análise de alguns elementos estruturais das narrativas.

\section{A noção de resistência para os estudos pós-coloniais}

Os estudos pós-coloniais surgem como uma corrente crítica que com uma abordagem alternativa busca compreender a influência do fenômeno imperialista e colonizador seja em uma perspectiva político-econômica ou cultural (BONNICI, 2009; LOOMBA, 1998) e (ASHCROFT; GRIFFITHS; TIFFIN, 2002). Para estes pesquisadores a literatura pós-colonial têm como centro o combate a linguagem imperial e colonizadora que domina a cultura e os povos. São estudos que tem como característica a resistência e a subversão do canônico (ASHCROFT; GRIFFITHS; TIFFIN, 2002), buscando sair de discursos que colocam grupos minoritários em uma situação periférica e opressora. Conforme Bonnici (2009), Harlouw (1987) e Bosi (2002) a literatura pós-colonial apresenta-se como estratégia de resistência na qual o sujeito se coloca em um contexto sócio-histórico-cultural e nesta escrita resistente os "valores mais autênticos afloram no texto" (BOSI, 2002, p.135).

O termo resistência foi pensando na década de 30 e 50. Nesta época ocorreu o embate de numerosos intelectuais contra o fascismo e vários sistemas governamentais totalitários. Foi uma época em que se manifestou a chamada "literatura de resistência". Bosi (2002), Bhabha (1998) e Harlow (1987) possuem semelhanças na forma de compreender o termo resistência que tem seu início em fatos históricos de guerra, anti-imperialismo, descolonização e libertação. Porém conforme a militância avança nas conquistas as literaturas emergentes começam a surgir e serem estudadas. A resistência passa a manifestar-se na literatura não somente como tema, mas como texto narrativo que na sua linguagem interna é reveladora de uma tensão evidenciando a resistência. Segundo Bosi (2002) deve-se "detectar 
em certas obras, escritas independentemente de qualquer cultura política militante, uma tensão interna que as faz resistentes, enquanto escrita, e não só, ou não principalmente, enquanto tema" (BOSI, 2002, p. 129).

$\mathrm{Na}$ tradução adaptada na literatura surda e na literatura infantil de Ondjaki veremos que a resistência não se apresenta como tema, mas é um construto inerente da narrativa na qual encontraremos valores culturais e linguísticos de um grupo minoritário que faz da literatura umas das estratégias de resistência para evocar sua diferença (BONNICI, 2009).

Bosi (2002), assim como Harlow (1987) quando tratam da resistência como construto da narrativa, propõem um alargamento da visão no que concerne a literatura de resistência. Assim é possível encontrarmos em determinadas obras a independência de qualquer sistema político militante, de forma que a narrativa se torna escrita de resistência, pois coloca em cena personagens, valores culturais e linguísticos que instauram a tensão na narrativa entre o sujeito e a mentalidade dominante.

São literaturas que possuem uma manifestação engajada em causas sociais. É um discurso literário em que encontraremos aspectos do contexto cultural e social que fazem parte dos grupos em questão e que, por meio da literatura se manifestam em representações linguístico-culturais. Ambas são literaturas de "ex-colônias" (BONNICI, 2002, p. 28) seja em sua forma simbólica, como é o caso da literatura surda que teve a língua oral imposta por séculos, manifestando um poder colonial simbólico por meio da língua ou por meio do colonialismo territorial, como é o caso da Angola, trazendo guerras, sofrimento e interferências na cultura.

Verificaremos a seguir as evidências de resistência entre as obras Adão e Eva da literatura surda e Ynari: a menina de cinco tranças de Ondjaki, considerando as representações linguístico-culturais que a narrativa revela.

\section{Elementos de resistência em Adão e Eva e Ynari: a menina de cinco tranças}

A obra Adão e Eva de Lodenir Karnopp e Fabiano Rosa não possui versão em LIBRAS. A história é uma adaptação do mito da criação cristã e traz a perspectiva da criação do mundo a partir da Língua de Sinais. Veremos que nesta narrativa a espacialização é objetiva e o "gradiente sensorial" (BORGES FILHO, 2007) que mais se destaca na narrativa é a visão. A visão é o sentido pelo qual o ser humano entra em contato com o mundo e o sentido pelo qual o surdo escuta o mundo. Já na obra Ynari: a menina de cinco tranças a espacialização é objetiva e subjetiva e mais de um gradiente sensorial é valorizado na obra, entre os principais estão a visão e a audição. 
Como dito anteriormente, a visão é o gradiente sensorial mais valorizado na obra Adão e Eva isto fica evidente já na primeira página, em que encontramos o "sinal identificatório" das personagens principais Adão e Eva.

Já na obra Ynari: a menina de cinco tranças o autor evidencia a visão e audição; a adjetivação da personagem principal é o constante diálogo com o "homem pequenino". O autor nos remete aos contos de fadas quando inicia a narrativa: "Era uma vez uma menina que tinha cinco tranças lindas e se chamava Ynari. Ela gostava de passear perto da aldeia, ver o campo, ouvir os passarinhos e sentar-se junto à margem do rio" (ONDJAKI, 2010, p. 6).

Ynari é linda, tem tranças. A ilustração da capa contribui com a adjetivação do autor para com a personagem durante todo o texto apresentando-a como uma menina negra, com roupas típicas do continente africano, tranças trabalhadas como é próprio da cultura de Luanda, assim como na obra Adão e Eva o espaço criado pelo autor onde se passa a história é a natureza. No caso da obra Ynari dois grandientes são mais valorizados no texto, a visão e audição.

Um glossário é disponibilizado ao leitor no final de cada obra. Em Adão e Eva o léxico é disponibilizado em sinais, pois algumas palavras podem ser desconhecidas do leitor, fato que também encontramos na obra Ynari, nas últimas páginas há disponível para o leitor, um glossário com o significado das palavras próprias da cultura africana que aparecem no texto. Dessa forma, fica evidenciado que as obras podem ser acessadas por crianças em fase de letramento tanto da língua de sinais como da língua portuguesa.

Nos dois textos a língua manifesta-se como uma das evidências de resistência de um determinado grupo cultural. A apresentação dos elementos culturais em ambos os textos promove a identificação cultural. Isto significa dizer que a identidade apresentada está no campo da representação e esta inclui "as práticas de significação e os sistemas simbólicos por meio dos quais os significados são produzidos" (WOORDWARD, 2012, p. 17). Assim, ao apresentar a origem das línguas de sinais, Deus é colocado em uma posição de usuário da Língua de Sinais e Ynari ao ser apresentada como criança de tranças, linda, com lábios carnudos e negros, promove a identificação das crianças do continente africano.

Na primeira parte da narrativa Deus faz uso da Língua de Sinais durante a criação do mundo: "No início de todas as coisas, Deus criou os céus e a Terra" (KARNOPP; ROSA, 2011, p. 8). A imagem, neste caso, completa a história: observar como a escrita e a imagem acontecem no texto é "investigar os diversos efeitos de sentido criados no espaço pelo narrador” (BORGES FILHO, 2007, p. 33). Neste espaço criado pelo narrador encontramos 
alguns deslocamentos ou percursos espaciais: o primeiro deles é o momento criacional, quando Deus faz uso da língua de sinais e cria o mundo.

Para Stuart Hall (2011) "o sujeito sempre fala a partir de locais objetivos que ocupam entre o mundo social e cultural" (HALL, 2011, p. 12). As duas figuras mostram o local cultural de onde os autores estão narrando, isto é, o lócus de enunciação, ou seja, o lugar de onde o narrador fala.

No primeiro momento da narrativa na obra Adão e Eva a mão esquerda na forma passiva de articulação do sinal, toca a terra e a mão direita articula o sinal como, uma interrogativa; vê-se o desenho de símbolos interrogativos em torno da mão sinalizante. Ao representar Deus como usuário da Língua de Sinais, se produz, por meio da literatura, a problematização ou questionamento sobre a diferença cultural dos utentes da LIBRAS em relação aos ouvintes que, por séculos, nos espaços educativos, os proibiram de fazer uso dos sinais, colocando a língua de sinais numa posição de inferioridade em relação às línguas orais. Assim, ao representar Deus como usuário de Língua de Sinais, o surdo se desloca linguisticamente para uma posição de poder. $\mathrm{O}$ espaço representado pelo narrador facilita esta visão, pois Deus cria o mundo fazendo uso da língua de sinais ao invés de uma língua oral.

Na narrativa Ynari: a menina de cinco tranças podemos verificar por meio da ilustração que acompanha a narrativa que a personagem Ynari pertence ao povo africano, tem pele negra, as roupas e o cabelo trançado com pequenos adereços coloridos, pulseira no pulso e no tornozelo, e a saia mostra a forma de se vestir das crianças africanas. O encontro com o "homem pequeno" revela que sua origem também é de uma aldeia junto à nascente do rio e lá, todos são pequenos.

Conforme Woordward (2012), a representação é uma forma de atribuir sentido e na literatura, por meio das narrativas, ocorre a apresentação de um espaço de identificação da comunidade surda na obra Adão e Eva e das crianças angolanas na obra Ynari: a menina de cinco tranças, distinguindo a primeira linguisticamente da comunidade ouvinte e a segunda de outros povos. Por serem literaturas emergentes e apresentarem em suas narrativas aspectos linguístico-culturais dos surdos e do povo africano, estas narrativas podem ser consideradas textos pós-coloniais, pois, conforme Bhabha (1998), "no texto pós-colonial, o problema da identidade retoma como um questionamento persistente do enquadramento, do espaço de representação, onde a imagem [...] é confrontada por sua diferença, seu Outro" (BHABHA, 1998, p. 71).

A identidade aqui não é entendida numa perspectiva psicanalítica, mas a partir da 
concepção Woordward (2012), como marcação de diferenças estabelecidas por meio das representações culturais que podem ser instituídas por meio língua, tendo como resultado uma produção simbólica; a identidade torna-se enunciado que promove uma identificação cultural consigo mesmo e com o outro.

A instituição da diferença por meio da língua é visível em ambos os textos e constitui-se um segundo deslocamento nas narrativas: na narrativa Adão e Eva, criado por um Deus usuário de sinais, Adão, também faz uso da língua de sinais, tentando se comunicar com uma onça. "Adão tentou se comunicar com a onça, mas ela só rugia" (KARNOPP; ROSA, 2011, p. 12). O animal fica confuso, sem entender Adão e apresenta expressões faciais que revelam esta incompreensão da língua de sinais.

O deslocamento marcado pela diferença linguística apresenta-se na obra Ynari: a menina de cinco tranças, quando a menina encontra um "homem pequenino" e pergunta: "E tu, de onde vens? [...] "Venho daquela aldeia ali - apontou na direção das cubatas" (ONDJAKI, 2010, p. 8). Cubatas, segundo o autor, são casas cobertas de palhas, abrigo típico das aldeias no continente africano. Após conversar com o "homem pequeno", Ynari retorna preocupada para sua aldeia, adormecendo no colo de sua avó. Neste ponto da narrativa fica evidente que Ynari pertence a uma das muitas comunidades étnicas africanas. A avó, com o turbante azul na cabeça, também pertencente a mesma tribo de Ynari, pergunta para menina se a causa de sua tristeza são os antílopes que estavam sendo mortos na caçada. Para o povo de Ynari o antílope é denominado olongo: "Estás triste por causa dos olongos?", Ynari responde: "Não, hoje o meu coração ficou triste" (ONDJAKI, 2010, p. 11).

As ilustrações complementam o texto e contribuem na adjetivação das personagens, valorizando uma marca cultural e linguística das comunidades em questão. A ilustração que acompanha o texto nos permite verificar a representação do "grande do coração" saindo do peito do homem pequeno, reforçando assim, a ideia de que o coração, mesmo dentro das pessoas, não é pequeno, pois, conforme a fala do "homem pequeno", o coração guarda grandes sentimentos.

\footnotetext{
“Conhecer a palavra coração?" bate dentro de nós - e mostrou no seu peito onde o coração batia. - Claro, e... o coração é pequeno para ti?

- É ... e não é! Cabe tanta coisa lá dentro, o amor, os nossos amigos, a nossa família..

- Vês? - disse o homem menos que ela- Ás vezes uma coisa pequenina pode ser tão grande... (ONDJAKI, 2012, p. 9)
}

A ideia do coração grande é evidenciada na gravura em contraste com o homem pequeno que mostra o coração povoado e não vazio. 
$\mathrm{Na}$ narrativa Adão e Eva, várias marcas culturais do povo surdo também são evidenciadas: "Adão sinalizava para o papagaio, tentando se comunicar, mas o papagaio só cantava" (KARNOPP; ROSA, 2011, p. 13). A expressão facial é considerada um elemento gramatical. As expressões não manuais são consideradas como elemento gramatical e seu uso é essencial nos discursos em línguas de sinais (QUADROS; KARNOPP, 2004). O pássaro apresenta traços de dúvida, expresso pelo franzir das sobrancelhas, que é uma marcação obrigatória, feita pelo sinalizante, nos discursos interrogativos. A valorização dos aspectos visuais é muito relevante, visto que as línguas de sinais são de modalidade visuo-espacial.

Assim, a tradução adaptada sob a forma da narrativa Adão e Eva e a narrativa de Ynari: a menina de cinco tranças, podem ser consideradas, enquanto obras literárias, estratégia de deslocamento da relação colonial linguística entre o surdo e o ouvinte - a comunidade angolana e o colonizador português, pois, nestas obras, ocorre a afirmação das diferenças linguístico-culturais dos diferentes grupos sociais em questão. Como aduz Bhabha (1998), é na afirmação das diferenças: "onde se revela a autoridade cultural como conhecimento de uma verdade referencial no momento da enunciação que produz a identificação cultural, uma articulação de novas exigências, estratégias culturais e significados" (BHABHA, 1998, p. 64).

A apresentação das diferenças linguístico-culturais nas narrativas adaptadas nas obras Adão e Eva e Ynari é a enunciação que pode ser geradora da identificação cultural por parte dos utentes da LIBRAS e das crianças africanas, inspirando os leitores a articular novos significados e exigências em relação à comunidade surda, à língua de sinais, às pessoas ouvintes e suas posturas diante das pessoas surdas e as comunidades africanas frente as situações de guerra.

A solidão e o sentimento de minoria linguística, bem como o sofrimento em razão da guerra vêm na forma de terceiro deslocamento nas narrativas, no momento em que Adão se senta aos pés de uma árvore e Deus se comove com sua tristeza, e no momento em que Ynari escuta que um grupo de homens começa a disparar contra outro grupo de homens em cima da montanha. Ynari observa o sofrimento de quem está em meio a guerra

A fim de minorar a tristeza e despertar, novamente, a alegria em Adão, Deus cria Eva, também usuária de sinais. Já para a personagem Ynari, a fim de dar fim a guerra, a menina é levada ao "portão de árvore" (ONDJAKI, 2010, p.17), onde começa a aldeia do homem pequenino e lá é dada a ela por meio de uma "velha, muito velha que destrói as palavras" (ONDJAKI, 2010, p.19), a palavra "permuta”. Na tradição africana conforme Bá 
(2010, p. 195) é "aos velhos sábios da comunidade, em suas audiências secretas, que cabe o difícil dever de "olhar as coisas pela janela certa".

A entrada pelo "portão da árvore" expressa a ideia dos lugares misteriosos e secretos que vivem os sábios da aldeia e que ajudará Ynari a olhar e dar a ela a palavra secreta que ela mesma deverá descobrir para por fim a guerra. Ynari pertencia a uma tribo e para os povos africanos "cada povo possui como herança dons particulares, transmitidos de geração em geração através da iniciação" (BÁ, 2010, p. 193). Ynari recebe a palavra como herança e dom; assim é iniciada na cultura e tradição de seu povo e será por meio da palavra mágica que tem o poder de conservar e destruir que irá por fim a guerra. Em Adão e Eva, outro aspecto cultural da comunidade surda é apresentado: o toque no ombro. "Adão estava sentado, e de repente alguém tocou seu ombro" (KARNOPP; ROSA, 2011, p. 17). O aceno de mão, assim como um leve toque no ombro é uma marca comportamental da comunidade surda para chamar a atenção do outro com quem se quer comunicar.

Um elemento linguístico-cultural que ocorre como quarto deslocamento é revelado no texto: a expressão "calma". Eva percebe que Adão está assustado e sinaliza: "Calma, sou Eva!” (KARNOPP; ROSA, 2011, p. 18). O sinal de calma é uma expressão idiomática na comunidade surda, não apenas uma expressão imperativa. Em outras elaborações literárias surdas, como por exemplo, Piadas em LIBRAS, produzidas e gravadas pela Federação Nacional de Educação e Integração dos Surdos - FENEIS, por instrutores surdos, na piada Árvore Surda e também na Coleção Educação de Surdos: Contando histórias em LIBRAS, na história traduzida Curupira, publicada pelo Ministério da Educação e Cultura- MEC, observamos esta mesma expressão "calma”, não como um imperativo, mas uma expressão presente nos discursos dos surdos utentes de LIBRAS.

Na obra Ynari o quarto deslocamento é apresentado no respeito à figura da pessoa mais velha da tribo que vem a ser um traço cultural dos povos africanos. Observamos que quando a menina é levada para a aldeia do homem pequeno. Nesta aldeia cada habitante é dotado de uma palavra mágica. O homem pequenino, por meio das palavras transformava as armas de fogo em armas de barro fazendo delas algo inútil para a guerra, mas isto não era o suficiente para por fim a guerra. Ynari é apresentada à mulher mais velha da aldeia e pede a ela uma palavra mágica. A sábia velha explica que toda palavra mágica surgiu do maior desejo de cada um. O maior desejo da menina era por fim à guerra e por isso recebe a palavra "permuta". Temos na obra dois elementos importantes para os povos africanos a palavra e o respeito aos mais velhos. 
Ao longo do texto, há ênfase no valor das palavras para por fim à guerra. A palavra permite resistir a guerra. Para Bá (2010, p. 173) a palavra falada "pode criar a paz, assim como pode destruí-la. É como um fogo. Uma única palavra imprudente pode desencadear uma guerra, do mesmo modo que um graveto em chamas pode provocar um grande incêndio". Já na obra Adão e Eva há ênfase no sinal pois, para a comunidade surda a palavra está numa modalidade visual e ganha sentido por meio do sinal. Tanto a comunidade surda, como as tribos africanas são caracterizadas por possuírem tradição oral, ou seja, o conhecimento é passado por meio da palavra, no caso das comunidades africanas e por meio do sinal, no caso da comunidade surda. Conforme Bá (2010) as sociedades de tradições orais possuem uma ligação forte com a palavra.

[...] Lá onde não existe a escrita, o homem está ligado à palavra que profere. Está comprometido por ela. Ele é a palavra, e a palavra encerra testemunho daquilo que ele é. A própria coesão da sociedade repousa no valor e no respeito pela palavra [...] (BÁ, 2010, p. 168).

Para o africano a palavra, além de um valor moral, tem relação com o sagrado. Segundo Bá (2010) “A tradição oral é a grande escala da vida, e dela recupera e relaciona todos os aspectos (BÁ, 2010, p. 169).

Em ambos textos revela-se outro elemento linguístico-cultural que também se apresenta como elemento de resistência: a criação de sinais no texto Adão e Eva e o fim das guerras nas aldeias por meio da palavra e do corte de cada trança de Ynari. Na obra Adão e Eva lê-se: "Estavam felizes no Paraíso e começaram a criar sinais para todas as coisas que viam. Do encontro de Adão e Eva, surgiu a Língua de Sinais do Paraíso (LSP)” (KARNOPP; ROSA, 2011, p. 19). Os sinais são criados em comunidade, por usuários surdos. Aqui é possível deduzir que Adão e Eva são surdos e dão início à Língua de Sinais do Paraíso; isto só acontece com a chegada de Eva. Não há uma institucionalização dos sinais de forma isolada e solitária, mas em comunidade.

Enquanto vivia sozinho no paraíso, Adão não criou sinais, apenas fazia uso de sinais; somente com a criação de Eva, e juntos, passaram a criar sinais, revelando esta ação como um elemento cultural dos usuários dessa língua. Já no texto de Ynari, a menina dotada da palavra mágica "permuta" visita as cinco tribos, cada uma delas está com um dos sentidos comprometidos. Cada vez que Ynari permuta uma de suas tranças a aldeia tem o sentido perdido devolvido: “[...] A fogueira estava acesa, já todos tinham posto o seu bocadinho de água na cabaça, quando Ynari disse algumas palavras, e depois ouviu-se a palavra permuta. Com a catana do mais velho ela cortou uma trança e deitou-a na enorme cabaça." (ONDJAKI, 
2010, p. 30).

A valorização da comunidade está presente em ambos os textos. No primeiro, quando Adão encontra Eva ocorre também a oportunidade de institucionalização dos Sinais do Paraíso, reforçando a importância da comunidade surda para os utentes da LIBRAS e na obra Ynari as comunidades recuperam os sentidos perdidos por meio da palavra permuta, falada por Ynari e, com isso, acabam com a guerra e reconstroem a vivência de comunidade nas aldeias. A palavra se revela como elemento mágico que conserva ou destrói. Segundo Bá (2010) “a tradição, pois, confere a Kuma, a Palavra, não só um poder criador, mas também a dupla função de conservar e destruir. Por essa razão a fala, por excelência é o grande agente ativo da magia africana" (BÁ, 2010, p. 173).

A criação dos sinais na obra Adão e Eva e o momento das permutas das tranças na história de Ynari, nos remete ao processo de "enunciação cultural" (BHABHA, 1998) que por meio da tradução adaptada que na literatura surda e da narrativa de Ondjaki conduz à construção de um discurso de resistência da realidade social que traz à reflexão as diferenças culturais, nas quais os enunciados culturais e sociais são também reconhecidos como sistemas de identificação que, por sua vez, produzem campos de forças. Dessa forma, a narrativa adaptada surda e a obra Ynari de Ondjaki tornam-se elemento de identificação cultural por meio do qual encontramos uma forma de enfrentamento, um questionamento da colonização linguística enfrentada pela comunidade surda e pelos povos africanos. Há uma enunciação de uma nova perspectiva em perceber como as diferenças culturais são reveladas, produzindo um "terceiro espaço" (BHABHA, 1998) promovendo, assim, a possibilidade de questionamento. Este terceiro espaço ocorre nas narrativas quando os autores se apropriam da língua do colonizador, constroem seus textos e os apresentam numa nova perspectiva, proporcionando outros olhares possíveis, apresentando um entre-lugar.

\footnotetext{
A intervenção do Terceiro Espaço da enunciação que torna a estrutura de significação e referência um processo ambivalente, destrói esse espelho da representação em que o conhecimento cultural em geral revelado como um código integrado, aberto em expansão. Tal intervenção vai desafia de forma bem adequada nossa noção de identidade histórica da cultura como forma homogeinizante, unificadora, autenticada pelo passado originário mantido vivo na tradição nacional de um povo (BHABHA, 1998, p. 67).
}

É neste terceiro espaço ou entre-lugar que se revelam as diferenças linguísticoculturais, uma forma de deslocamento da relação colonial linguística entre ouvinte e surdo, povo africano e povo europeu e aí também são reveladas as relações de poder entre as línguas (línguas orais e línguas de sinais/línguas africanas e língua portuguesa européia). A literatura 
torna-se um espaço de "abertura de outro lugar cultural e político de enfrentamento" (BHABHA, 1998, p. 62).

Em suma, podemos dizer que com a teoria pós-colonial abre-se a possibilidade de encontrar na literatura infantil evidências de resistência a partir dos elementos linguísticoculturais que a narrativa apresenta, nos remetendo a um novo olhar e novas perspectivas para a compreensão da literatura infantil e também para a quebra de sentidos e significados no que se refere a grupos minoritários e linguisticamente rechaçados pela sociedade capitalista.

\section{Considerações Finais}

As duas obras possuem proximidades no que se refere as evidências de resistência que se apresentam como um construto dentro da narrativa, expressando por meio de uma escrita a resistência ao poder colonial através de diversos elementos linguístico-culturais, dentre elas a língua que, para cada cultura aqui tratada tem seu valor específico e se encontra na força de seu sentido ao ser sinalizada ou pronunciada para a comunidade surda. Ser utente da LIBRAS é trazer consigo uma identidade, uma forma de pensar e existir no mundo e para o africano a palavra além de construir ou destruir vem carregada do elemento mágico aproximando-a do sagrado.

A obra Adão e Eva e a obra Ynari mostram comunidade de tradições orais que se conservam por meio da memória falada ou sinalizada, isto é evidente na forte presença do elemento comunitário nas duas narrativas, evidenciando a importância do coletivo na vida de quem pertence a estas comunidades ou grupos sociais.

Por fim, ao problematizar a diferença, a narrativa adaptada na literatura surda e na obra Ynari de Ondjaki, podem expressar o desejo de legitimar sua língua e cultura nos valores culturais que são apresentados nas narrativas como elementos de enunciação da diferença linguístico-cultural, articulando novas exigências e seus significados em conceber a criação e enfrentar a guerra. Esta forma de enunciar por meio da literatura questiona e gera um entrelugar por meio da percepção dos ícones culturais que vêm realocados em nome de uma tradição cultural.

\section{Referências}

ASHCROFT, Bill; GRIFFITHS, Gareth; TIFFIN, Helen. The Empire writes back. Theory and practice in post-colonial literatures. 2. ed. London: Routhedge, 2002.

BÁ, Hampaté A. A tradição Viva. In: UNESCO. História geral da África, I: Metodologia e pré-história da África. 2. ed. Brasília: UNESCO, 2010, p. 181-218. 
BASSNET, Susan. Estudos de Tradução. Lisboa: Fundação Calouste Gulbenkian, 2003.

BHABHA, Homi K. O local da cultural. Belo Horizonte: UFMG, 1998.

BONNICI, Thomaz. Resistência e Intervenção nas literaturas pós-coloniais. Maringá: Eduem, 2009.

BORGES FILHO, Ozíris. Espaço e Literatura: introdução à Topoanálise. São Paulo: Ribeirão Gráfica e Editora, 2007.

BOSI, Alfredo. Literatura de Resistência. São Paulo: Companhia das Letras, 2002.

HALL, Stuart. A Identidade Cultural na Pós-Modernidade. 11. ed. Rio de Janeiro: DP\&A, 2011.

HARLOW, Barbara. Literature Resistence. New York and London: Methuen, 1987.

HOLCOMB, Thomas K. Introduction to American Deaf Culture. New York: Oxford, 2013.

KARNOPP, Lodenir Becker. Produções culturais dos surdos: análise da literatura surda. Cadernos de Educação. Pelotas, n. 36, p. 155-174, maio/ago. 2010.

KARNOPP, Lodenir Becker; ROSA, Fabiano. Adão e Eva. Il. Maristela Alano. 2. ed. Canoas: ULBRA, 2011.

KARNOPP, Lodenir Becker; ROSA, Fabiano; SILVEIRA, Carolina Hessel. Rapunzel Surda. 2. ed. Canoas: ULBRAS, 2011.

Cinderela Surda. 2. ed. Canoas: ULBRA, 2007

LOOMBA, Ania. Colonialism/postcolonialism. New York: Routledge, 1998.

MOURÃO, Cláudio Henrique Nunes. Literatura Surda: produções culturais dos surdos em Língua de Sinais. Porto Alegre. 2011. Disponível em: $<$ http://www.lume.ufrgs.br/handle/10183/32311>. Acesso em: 24 jan. 2015.

ONDJAKI. O voo do golfilho. São Paulo: Companhia das Letrinhas, 2012.

. Ynari: a menina de cinco tranças. São Paulo: Companhia das Letrinhas, 2010.

O leão e o coelho saltitão. São Paulo: Companhia das Letrinhas, 2009.

QUADROS, Ronice Muller. KARNOPP, Lodenir Becker. Lingua Brasileira de Sinais, Estudos Linguísticos. Porto Alegre: Artes Médicas, 2004.

STROBEL, Karin. As imagens do outro sobre a cultura surda. 3. ed. Florianópolis: Ed. da UFSC, 2013.

WOODWARD, Kathryn. Identidade e diferença: uma introdução teórica e conceitual In: SILVA, Tomaz Tadeu; HALL, Stuart; WOODWARD, Kathryn. Identidade e Diferença. A perspectiva dos Estudos Culturais. 12. ed. São Paulo: Vozes, 2012. 
[Recebido em 27 de janeiro de 2016 e aceito para publicação em 29 de abril de 2016]

\section{Linguistic-cultural evidence resistance in post-colonial children's literature: deaf literature and Ondjaki}

Abstract: This article identifies linguistic-cultural representations of resistance in the narrative Adão e Eva of authors Lodenir Karnopp and Fabiano Rosa, the deaf literature and Ynari: a menina de cinco tranças of angolan author Ondjaki. For this, we use the comparativist approach bringing evidence of resistance in the works from the perspective of post-colonial studies. In the first part we contextualize the two narratives, then we use the term resistance from the post-colonial studies and, finally we do the analysis of the narratives. In order to define the elements of comparative analysis, we use some aspects of topoanalysis listed by Ozíris Borges Filho limiting our study to the strength of evidence manifested in the narratives by characters and the ambiance created by the authors, trying identify cultural values and language that are expressed in the narratives. We will see that both Adão e Eva and Ynari have textual elements that demonstrate linguistic and cultural values and the authors make literature a strategy for resistance.

Keywords: Deaf Literature. Ondjaki. Postcolonialism. Resistence.

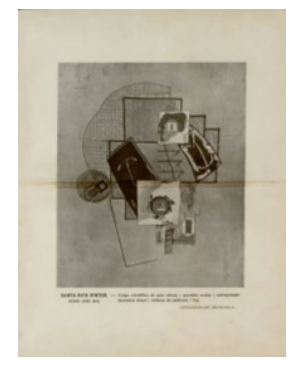

